\title{
Bacterial isolates and their antibiotic susceptibility patterns among patients with pus and/or wound discharge at Gondar university hospital
}

Dagnachew Muluye ${ }^{1 *}$, Yitayih Wondimeneh ${ }^{1}$, Getachew Ferede ${ }^{1}$, Tesfaye Nega $^{2}$, Kasaw Adane ${ }^{1}$, Belete Biadgo ${ }^{1}$, Habtie Tesfa ${ }^{1}$ and Feleke Moges ${ }^{1}$

\begin{abstract}
Background: In spite of advances in control of infections, wound infections have not completely controlled due to many reasons. The widespread uses of antibiotics, together with the length of time over which they have been available have led to major problems of resistant organisms contributing to morbidity and mortality. This study was aimed to assess bacterial isolates and their drug susceptibility patterns from patients with pus and/or wound discharge.

Methods: A retrospective study was conducted at Gondar University Hospital from all individuals who provide pus and/or wound discharge sample from September, 2009 to August, 2012. Socio-demographic and laboratory results were collected from the University Hospital Microbiology Laboratory unit registration books by using a standard data collection format. Data were analyzed using SPSS version 20 software. P-value $\leq 0.05$ was considered statistically significant.

Result: A total of 628 study subjects were included in the study with bacterial isolation rate of 441 (70.2\%). Of all, 344 (54.8\%) were males. Two hundred eighty two (63.9\%) of the isolates were gram positive and 159 (36.1\%) were gram negative. About 331/ 441 (75.0\%) of the total isolates were Staphylococcus aureus (32.9\%), Coagulase Negative staphylococci (14.7\%), Streptococcus spp. (11.6\%), Escherichia coli (9.5\%), Klebsiella spp. (6.3\%). The result showed that 66.2\% of the isolates were resistant to tetracycline, followed $59.8 \%$ for ampicillin, $59.1 \%$ for cotrimoxazole, $51.7 \%$ for penicillin; least resistant being $6.3 \%$ for gentamycin.

Conclusion: High prevalence of bacterial isolates were found; S. aureus being the dominant. Most of the isolates were resistant to many of the antibiotics tested where all isolates of Pseudomonas spp. being resistant to two or more antibiotics. Antibiotic susceptibility test is necessary for effective control of wound infections.
\end{abstract}

Keywords: Pus, Wound discharge, Gondar University Hospital

\section{Background}

Infectious diseases still remain an important cause of morbidity and mortality among humans, especially in developing countries. Various species of bacteria live on human skin, gastrointestinal tract, in the nasopharynx and other parts of the body with less potential for causing disease because of first line defense within the body. Skin abrasion due to surgical procedure, trauma, burns, diseases, nutrition and other factors affect this first line defense and leads to microbial contamination results

\footnotetext{
* Correspondence: dagne24@gmail.com

'School of Biomedical and Laboratory Sciences, College of Medicine and Health Sciences, University of Gondar, P.O. Box 196 Gondar, Ethiopia

Full list of author information is available at the end of the article
}

infections [1]. As wound infections are largely hospital acquired and the infecting pathogens not only differ from country to country, but also vary from one hospital to another within the same country [2].

The problem of hospital acquired infection remains a serious health hazard worldwide. As described by World Health Organization (WHO) [3], it is one of the major sources of infectious diseases which results for the huge economic impact with significant rate of morbidity and mortality. Despite advances in control of infections, wound infections have not completely prevented due to the problem of drug resistance [4]. The widespread uses of antibiotics, together with the length of time over which they have 
been available, have led to major problems of resistant organisms contributing to morbidity and mortality [5].

Knowledge of the causative agents of wound infection has proven to be helpful in the selection of appropriate antimicrobial therapy and on infection control measures taken in health institutions [6]. Therefore, the present study aimed to evaluate the important causative agents of bacteria and their antibiotic susceptibility patterns which may be imperative as it guides the selection of an effective regimen for the treatment.

\section{Methods}

A retrospective study was conducted at Gondar University Hospital from September, 2009 to August, 2012. Gondar University Hospital is a teaching hospital that provides health service to over five million inhabitants in Northwest Ethiopia. All individuals who provide pus and/or wound discharge sample at Gondar University Hospital during the study period were the participants. Socio-demographic and laboratory results were collected from the University Hospital Microbiology Laboratory unit registration books by using a standard data collection format after checking the completeness of the data. Wound swabs and discharges were aseptically collected using sterile swab in a test tube and inoculated on to chocolate agar (incubated in $\mathrm{CO}_{2}$ enriched environment), blood agar and MacConkey agar. Plates were incubated at $37^{\circ} \mathrm{C}$ of 24 hours. Once pure colonies identified series of biochemical tests were performed for the isolation of the species following standard procedures [7].

\section{Antimicrobial susceptibility tests}

Antimicrobial susceptibility testing was performed using Muller-Hinton agar (Mumbai, India) plates as recommended by the Clinical and Laboratory Standards Institute (CLSI) [8]. The isolates were tested against chloramphenicol $(30 \mu \mathrm{g})$, ampicillin $(10 \mu \mathrm{g})$, ciprofloxacin $(5 \mu \mathrm{g})$, gentamicin $(10 \mu \mathrm{g})$, cotrimoxazole $(5 \mu \mathrm{g})$, tetracycline $(30 \mu \mathrm{g})$, nalldixic acid $(30 \mu \mathrm{g})$, Ceftriaxone $(30 \mu \mathrm{g})$, Norfloxacin $(30 \mu \mathrm{g})$. For gram-positive isolates, erythromycin $(15 \mu \mathrm{g})$, methicillin $(5 \mu \mathrm{g})$, vancomycin, $(30 \mu \mathrm{g})$, streptomycin $(10 \mu \mathrm{g})$ were included. Plates were incubated at $35-37^{\circ} \mathrm{C}$ for 24 hours. The zones of inhibition were measured and compared with the guidelines [8].

\section{Data analysis}

Data were cleaned manually and entered and analyzed by using SPSS version 20 software. Odds ratio and Chisquare test were employed. P-value $\leq 0.05$ was considered statistically significant.

\section{Ethical considerations}

Ethical clearance was obtained from the Institutional Review Board of University of Gondar. A supportive letter was also obtained from College of Medicine and Health Sciences and the University Hospital clinical director before collecting the data.

\section{Results}

A total of 628 study subjects were included in the study. Among these, 284 (45.2\%) were females and 344 (54.8\%) were males with the age range of 1 month to 81 years. Among 628 study subjects, bacterial pathogens were isolated from 441 patients with the isolation rate of $70.2 \%$ [Table 1]. Culture positivity rate from 2009-2012 in the bacteriology laboratory of the present study demonstrate the maximum isolation rate in 2009 which was $73.9 \%$ and a slightly lower in 2012 which was 69.3\% [Table 1]. Two hundred eighty two (63.9\%) of the isolates were gram positive and 159 (36.1\%) were gram negative. About 331/ $441(75.0 \%)$ of the total isolates were Staphylococcus aureus, Coagulase Negative Staphylococci (CNS), Streptococcus spp, Escherichia coli and Klebsiella spp. Among these $S$. aureus accounts $32.9 \%$ followed by CNS (14.7\%), Streptococcus spp. (11.6\%), E. coli (9.5\%), Klebsiella spp. (6.3\%), streptococcus pyogenes (4.8\%), Pseudomonas spp. (1.8\%).

Most of the isolates were resistant to many of the antibiotics tested. The result showed that $66.2 \%$ of the isolates were resistant to tetracycline, followed $59.8 \%$ for ampicillin, $59.1 \%$ for cotrimoxazole, $51.7 \%$ for penicillin; least resistant being $6.3 \%$ for gentamycin. Among isolates tested, $18.3 \%$ of the isolates are becoming resistant to ceftriaxone and $33.3 \%$ for vancomycin [Table 2]. Only twenty isolates of $S$. aureus were tested for Methicillin susceptibility, of which, $4(20 \%)$ were resistant and 16 (80\%) were sensitive.

Among resistant isolates to more than one antibiotic, the most common pathogen was Pseudomonas spp, (100\%); followed by S. pyogenes (85.8\%); Enterobacter spp. (84.2\%);

Table 1 Total pus and/or wound discharge and cultured positivity rate at Gondar University Hospital, 2009-2012

\begin{tabular}{|c|c|c|c|c|c|c|}
\hline \multicolumn{2}{|c|}{ Year assessed } & \multicolumn{2}{|c|}{ Type of sample (\%) } & \multicolumn{2}{|c|}{ Culture status (\%) } & \multirow[b]{2}{*}{ Total } \\
\hline & & Wound swab & Pus/discharge & Positive & Negative & \\
\hline \multirow[t]{5}{*}{ Year } & 2009 & $114(72.6)$ & $43(27.4)$ & $116(73.9)$ & $41(26.1)$ & $157(100)$ \\
\hline & 2010 & $148(73.3)$ & $54(26.7)$ & $144(71.3)$ & $58(28.7)$ & $202(100)$ \\
\hline & 2011 & $96(61.9)$ & $59(38.1)$ & $102(65.8)$ & $53(34.2)$ & $155(100)$ \\
\hline & 2012 & $62(54.4)$ & $52(45.6)$ & 79 (69.3) & $35(30.7)$ & $114(100)$ \\
\hline & Total & $420(66.9)$ & $208(33.1)$ & $441(70.2)$ & $187(29.8)$ & $628(100)$ \\
\hline
\end{tabular}


Table 2 Antibiotic susceptibility patterns of isolates from pus and/or wound discharge for commonly used antibiotics at Gondar University Hospital, 2009-2012

\begin{tabular}{|c|c|c|c|c|c|c|c|c|c|c|c|c|c|}
\hline \multirow{2}{*}{$\begin{array}{l}\text { Culture } \\
\text { results }\end{array}$} & \multicolumn{13}{|c|}{ Antibiotic susceptibility patterns (\%) } \\
\hline & AMP & CRO & CAF & CIP & $\mathrm{E}$ & $\mathrm{CN}$ & MET & NOR & PG & SXT & TTC & VAN & NA \\
\hline Susceptible & $151(40.2)$ & $312(81.7)$ & $240(83.3)$ & $305(76.3)$ & $165(65.2)$ & $192(93.7)$ & $30(69.8)$ & $194(74.6)$ & $116(48.3)$ & $140(40.9)$ & $101(33.8)$ & $20(66.7)$ & $31(53.4)$ \\
\hline Resistance & $225(59.8)$ & 70 (18.3) & $48(16.7)$ & $95(23.7)$ & $88(34.8)$ & $13(6.3)$ & $13(30.2)$ & $66(25.4)$ & $124(51.7)$ & $202(59.1)$ & $198(66.2)$ & $10(33.3)$ & $27(46.6)$ \\
\hline Total & $376(100)$ & $382(100)$ & $288(100)$ & 400 (100) & 253 (100) & $205(100)$ & $43(100)$ & $260(100)$ & 240 (100) & $342(100)$ & 299 (100) & $30(100)$ & $58(100)$ \\
\hline
\end{tabular}

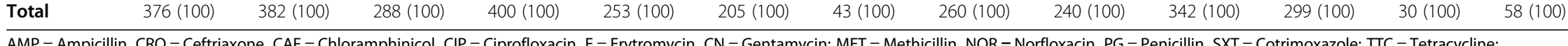
$\mathrm{VAN}=$ Vancomycin, $\mathrm{NA}=$ Nalidixic acid . 
Table 3 Multiple drug resistance patterns of isolates from pus and/or wound discharge at Gondar University Hospital, 2009-2012

\begin{tabular}{|c|c|c|c|c|c|c|c|c|}
\hline \multirow[t]{2}{*}{ Bacterial isolates } & \multicolumn{8}{|c|}{ Multiple drug resistance patterns of isolates $\mathrm{n}(\%)$} \\
\hline & Ro & R1 & R2 & R3 & R4 & $\geq$ R5 & Total & $\mathrm{MDR}^{*}$ \\
\hline S. aureus & $19(13.1)$ & $28(19.3)$ & $41(28.2)$ & $33(22.8)$ & $11(7.6)$ & $13(9)$ & $145(100)$ & 98 (67.6) \\
\hline E. coli & $4(9.5)$ & $3(7.1)$ & $10(23.8)$ & $7(16.7)$ & $7(16.7)$ & $11(26.2)$ & $42(100)$ & $35(83.4)$ \\
\hline CNS & $12(18.5)$ & $9(13.8)$ & $13(20.0)$ & $7(10.8)$ & $6(9.2)$ & $18(27.7)$ & $65(100)$ & $41(67.7)$ \\
\hline Streptococcus spp. & $3(5.9)$ & $6(11.8)$ & $9(17.6)$ & $13(25.5)$ & 10 (19.6) & $10(19.6)$ & $51(100)$ & $42(82.3)$ \\
\hline Proteus spp. & $4(20)$ & $3(15)$ & $3(15)$ & $7(35)$ & 0 & $3(15)$ & $20(100)$ & $13(65)$ \\
\hline Klebsiella spp. & $3(10.7)$ & $4(14.3)$ & $6(21.4)$ & $4(14.3)$ & $1(3.6)$ & $10(35.7)$ & $28(100)$ & $21(75)$ \\
\hline Enterobacter spp. & 0 & $3(15.8)$ & 0 & $4(21.1)$ & $2(10.5)$ & $10(52.6)$ & $19(100)$ & $16(84.2)$ \\
\hline Pseudomonas spp. & 0 & 0 & $1(7.7)$ & $3(23.1)$ & $4(30.8)$ & $5(38.4)$ & $13(100)$ & $13(100)$ \\
\hline Shigella spp. & 0 & $2(25.0)$ & $2(25.0)$ & 0 & $1(12.5)$ & $3(37.5)$ & $8(100)$ & $5(62.5)$ \\
\hline S. pyogenes & $1(4.7)$ & $2(9.5)$ & $4(19.1)$ & $10(47.6)$ & $1(4.8)$ & $3(14.3)$ & $21(100)$ & $18(85.8)$ \\
\hline Non-lactose fermentor G-ve rods & $4(13.8)$ & $8(27.6)$ & $6(20.7)$ & $5(17.2)$ & $1(3.4)$ & $5(17.3)$ & $29(100)$ & $17(58.6)$ \\
\hline Total & $50(11.3)$ & $68(15.4)$ & 95 (21.6) & $93(21.1)$ & $44(10.0)$ & $91(20.6)$ & $441(100)$ & $323(73.3)$ \\
\hline
\end{tabular}

${ }^{*} \mathrm{MDR}=$ Resistance to two or more antibiotics.

and E. coli $(83.4 \%)$. Fifty (11.3\%) of the isolates were sensitive to all drugs tested and $68(15.4 \%)$ were resistance to only one drug. However, among the total isolates, 323 (73.3\%) of them were resistant for two or more drugs tested and 91 (20.6\%) were resistant to more than 5 antibiotics tested. All isolates (100\%) of Pseudomonas spp. were resistant to 2 or more antibiotics followed by $S$. pyogenes $85.8 \%$, Enterobacter spp. 84.2\%, E.coli 83.4\%, Streptococcus spp., $82.3 \%$, S. aureus $67.6 \%$ [Table 3].

The majority of the isolates were in the age range of 21 to 30 years which was $113(25.6 \%)$ followed by in the age range of 1-10 years which was 95 (21.5\%); age range of $11-20$ which was 70 (15.9\%) [Table 4].
When we compared the culture positivity of the samples, pus /discharge samples were 2.38 times positive for bacterial isolates than wound swab samples $(\mathrm{OR}=2.38,95 \% \mathrm{CI}$ : 1.64-3.45, $\mathrm{P}<0.0001)$. Females were found to be 5.16 times more at risk to get infection than males $(\mathrm{OR}=5.16$, 95\% CI: 3.38-7.91, P < 0.0001). Age was also found to have significant association with a p-value of 0.003 [Table 4].

\section{Discussion}

Among 628 study subjects, bacterial pathogens were isolated from 441-patients with the isolation rate of $70.2 \%$. This was higher than the results reported by Mulu et al. in the same hospital [9]. This variation may be due to

Table 4 Bacterial isolates from pus and/or wound discharge based on age and sex category from patients at Gondar University Hospital, 2009-2012

\begin{tabular}{|c|c|c|c|c|c|c|c|c|c|c|c|}
\hline \multirow[t]{2}{*}{ Isolates } & \multicolumn{2}{|l|}{ Sex } & \multicolumn{9}{|c|}{ Age range in year (s) } \\
\hline & Male & Female & $<1$ & $1-10$ & $11-20$ & $21-30$ & $31-40$ & $41-50$ & $51-60$ & $>60$ & Total \\
\hline S. aureus & 74 & 71 & 18 & 32 & 34 & 36 & 9 & 13 & 2 & 1 & 145 \\
\hline CNS & 23 & 42 & 5 & 15 & 8 & 13 & 10 & 7 & 3 & 4 & 65 \\
\hline Streptococcus spp. & 24 & 27 & 4 & 15 & 7 & 12 & 3 & 6 & 1 & 3 & 51 \\
\hline E. coli & 17 & 25 & 4 & 5 & 5 & 14 & 2 & 7 & 4 & 1 & 42 \\
\hline NLFGNR & 11 & 18 & 5 & 7 & 2 & 7 & 4 & 3 & 1 & 0 & 29 \\
\hline Klebsiella spp. & 9 & 19 & 3 & 9 & 5 & 4 & 3 & 1 & 1 & 2 & 28 \\
\hline S. pyogenes & 11 & 10 & 1 & 2 & 3 & 11 & 0 & 4 & 0 & 0 & 21 \\
\hline Proteus spp & 9 & 11 & 0 & 3 & 3 & 6 & 3 & 1 & 1 & 3 & 20 \\
\hline Enterobacter spp. & 8 & 11 & 2 & 4 & 0 & 8 & 2 & 0 & 3 & 0 & 19 \\
\hline Pseudomonas spp. & 6 & 7 & 2 & 2 & 3 & 2 & 2 & 0 & 1 & 1 & 13 \\
\hline Shigella spp. & 2 & 6 & 2 & 1 & 0 & 0 & 3 & 1 & 1 & 0 & 8 \\
\hline \multirow[t]{2}{*}{ Total } & 194 & 247 & 46 & 95 & 70 & 113 & 41 & 43 & 18 & 15 & 441 \\
\hline & \multicolumn{2}{|c|}{$D f=11, \times 2=69.56, P<0.0001$} & \multicolumn{9}{|c|}{ Df $=77, \times 2=114.9, p$-value $=0.003$} \\
\hline
\end{tabular}

NLFGNR $=$ Non-lactose ferment or gram negative rods. 
little variation in laboratory facilities that we have currently. Among the total isolates, 282 (63.9\%) were gram positive and 159 (36.1\%) were gram negative. The predominant isolates in the present study was found to be S. aureus, which was $32.9 \%$, this was consistent with reports from India $30.1 \%$ and lower than Gondar hospital $65 \%[9,10]$. Although, S. aureus is predominant in both reports, the rate of isolation declined compared to the previous reports which was 65\% [9]. This low rate of isolation may be due to improved facilities of the hospital management at present in the infection control program.

Most of the isolates were resistant to many of the antibiotics tested. The result showed that $66.2 \%$ of the isolates were resistant to tetracycline, followed $59.8 \%$ for ampicillin, $59.1 \%$ for cotrimoxazole, $51.7 \%$ for penicillin; least resistant being $6.3 \%$ for gentamycin. Among isolates tested, $18.3 \%$ of the isolates are becoming resistant to ceftriaxone and $33.3 \%$ for vancomycin. Among resistant isolates to more than one antibiotic, the most common pathogen was Pseudomonas spp., $100 \%$; followed by S. pyogenes 85.8\%; Enterobacter spp. 84.2\%; and E. coli $83.4 \%$. Fifty $(11.3 \%)$ of the isolates were sensitive to all drugs tested and $68(15.4 \%)$ were resistance to only one drug. However, among the total isolates, 323 (73.3\%) were resistant for two or more drugs tested and 91 (20.6\%) were resistant to more than 5 antibiotics tested. This finding was supported by other studies done in Ethiopia $[11,12]$.

The majority of the patients who were positive for wound culture were in the age range of 21 to 30 years, which was $113(25.6 \%$, followed by in the age range of 1 10 years, which was 95 (21.5\%); age range of 11-20 which was 70 (15.9\%). Among 441 isolates, 194/334 (58.1\%) were from male and 247/284 (86.9\%) were from female patients. These results demonstrate that being female is found a risk factor for getting an infection by bacteria. Females were found to be 5.16 times at risk to get infected by bacteria than males. When we compared the culture positivity of the samples, pus/discharge samples were 2.38 times positive for bacterial isolates than wound swab samples. As to the limitation of this study; since it is a retrospective study some of the data registered were not as to the standard and were not included. We also fail to include more variables because of unavailability.

\section{Conclusion}

High prevalence of bacterial isolates were found from patients who provide pus and/or wound discharge sample in the study site S. aureus being the dominant. Most of the isolates were resistant to many of the antibiotics tested where all isolates of Pseudomonas spp. being resistant to two or more antibiotics. It is, therefore, necessary to do an antibiotic susceptibility test before drug prescription to effectively control wound infection.

\section{Abbreviations}

CNS: Coagulase negative staphylococci; MDR: Multidrug resistant; WHO: World Health Organization.

\section{Competing interests}

The authors have declared that no competing interests with respect to the authorship and/or publication of this research paper.

\section{Authors' contributions}

DM: participated in the conception and design of the study, data collection and analysis, interpretation of the findings and write up. YW, GF, TN, KA, BB, HT: Participated in the conception and design of the study and data collection, data analysis and interpretations of the findings. FM: Participated in the conception and design of the study, analysis and interpretations of the findings and drafting the manuscript. All authors reviewed and approved the final manuscript.

\section{Acknowledgement}

We acknowledge the staff of Gondar University Hospital Bacteriology laboratory staffs for their cooperation during data collection.

\section{Author details}

${ }^{1}$ School of Biomedical and Laboratory Sciences, College of Medicine and Health Sciences, University of Gondar, P.O. Box 196 Gondar, Ethiopia. ${ }^{2}$ Unit of Bacteriology, Gondar University Hospital, P.O. Box 196 Gondar, Ethiopia.

Received: 28 February 2014 Accepted: 4 September 2014 Published: 9 September 2014

\section{References}

1. Howard RJ, Ravitch MM, Steichen FM: Host against Infections. Current Problems in Surgery. New Eng J Med 1980, 12:1823-1830.

2. Ogunsola FT, Oduyebo O, Iregbu KC, Coker AD, Adetunji A: A review of nosocomial infections at LUTH; problems and strategies. J Nigerian Infection Control Association 1998, 1:213-217.

3. WHO: Surveillance, control and prevention of hospital acquired (nosocomial) infections. Report of an advisory group; 1981. BAC/NIC/81.6.

4. Thomas KH: Surgical Wound Infection, an Overview. Am J Med 1981, 70:712-718

5. Elmer WK, Stephen DA, William MJ, Schreckenberger PC, Winn WC: Antimicrobial Susceptibility testing in, colour atlas and textbook of Diagnostic Microbiology. 5th edition. Philadelphia: Raven Publisher; 1997:69-120.

6. Adebayor OS, Deboye OK, Emiola AR: Wound Infections in two Health Institutions in IIE-Ife, Nigeria: Results of a cohort study. Osto/Wound Manag 2003, 49:52-57.

7. Vandepitte A, El-Nageh MM, Stelling JM, Tikhomirov E, Estrela A: WHO Regional Publications, Eastern Mediterranean Series, Volume 15. Alexandria, Egypt: WHO Regional Publications, Eastern Mediterranean Series; 1996.

8. National Committee for Clinical Laboratory Standards: Performance standards for antimicrobial susceptibility testing. 7th edition. Wayne, PA: Approved standard M2-A7. National Committee for Clinical Laboratory Standards; 2000

9. Mulu A, Moges F, Tesema B, Kassu A: Pattern and multiple drug resistance of bacterial pathogens isolated from wound infection at University of Gondar teaching hospital, North west Ethiopia. Ethiop Medi J 2006 44:125-131.

10. Malik S, Gupta A, Singh KP, Agarwal J, Singh M: Antibiogram of Aerobic Bacterial Isolates from Post-operative Wound Infections at a Tertiary Care Hospital in India. J Infect Dis Antimicrob Agents 2011, 28:45-51.

11. Gebre-Selassie S: Antimicrobial resistance of clinical bacterial isolates in Southern Ethiopia. Ethiopian Med J 2007, 45:363-375.

12. Dagnachew M, Yitayih W, Getachew F, Feleke M, Tesfaye N: Bacterial isolates and drug susceptibility patterns of ear discharge from patients with ear infection at Gondar University Hospital, Northwest Ethiopia. BMC Ear Nose Throat Disord 2013, 13:10.

\section{doi:10.1186/1756-0500-7-619}

Cite this article as: Muluye et al:: Bacterial isolates and their antibiotic susceptibility patterns among patients with pus and/or wound discharge at Gondar university hospital. BMC Research Notes 2014 7:619. 